\title{
Rethinking the Problem of Cognition
}

\author{
Mikio Akagi
}

Revised, March 2017.

\begin{abstract}
The present century has seen renewed interest in characterizing cognition, the object of inquiry of the cognitive sciences. In this paper, I describe the problem of cognition - the absence of a positive characterization of cognition despite a felt need for one. It is widely recognized that the problem is motivated by decades of controversy among cognitive scientists over foundational questions, such as whether non-neural parts of the body or environment can realize cognitive processes, or whether plants and microbes have cognitive processes. The dominant strategy for addressing the problem of cognition is to seek a dichotomous criterion that vindicates some set of controversial claims. However, I argue that the problem of cognition is also motivated by ongoing conceptual development in cognitive science, and I describe four benefits that a characterization of cognition could confer. Given these benefits, I recommend an alternative criterion of success, ecumenical extensional adequacy, on which the aim is to describe the variation in expert judgments rather than to correct this variation by taking sides in sectarian disputes. I argue that if we had an ecumenical solution to the problem of cognition, we would have achieved much of what we should want from a "mark of the cognitive."
\end{abstract}

Keywords: Cognition; Mark of the cognitive; Cognitive science; Embodied cognition; Extended cognition; Conceptual analysis.

\section{The Problem of Cognition}

Cognitive science is the interdisciplinary study of something called "cognition." Cognitive scientists and other researchers traffic in talk about cognition and its cognates (cognitive states, processes, \&c.), and take these things, whatever, they are, to be their object of study. There is general agreement about the component disciplines of cognitive science-parts of psychology, 
computer science, neuroscience, artificial intelligence, philosophy, linguistics-and there is also agreement on which topics belong to cognitive science-e.g. perception, learning, memory, decision-making, language, motor control, \&c. However, there is no agreement about what cognition is (Adams and Aizawa 2001; Godfrey-Smith 2002; Bourgine and Stewart 2004; Prinz 2004; Lyon 2006; van Duijn et al. 2006; Adams and Garrison 2013; Buckner 2015). Many feel a need for more clarity than this. Fred Adams and Rebecca Garrison claim that it is "embarrassing to say the least for there to be a science of cognition... that is unable to say what constitutes cognition" (2013, 340). Jesse Prinz says that "It is scandalous that cognitive science has not settled on a definition of cognition" $(2004,41)$. This state of affairs, that we have no satisfying account of the nature or extension of cognition, despite a felt need for such an account, is the problem of cognition.

Some philosophers deny that there is any satisfying, unique solution to the problem of cognition (Chemero 2009, 212n8; Clark 2010, 62). Many share a common attitude that "there really isn't a lot at stake, scientifically, in our efforts to delineate the conceptual boundaries of cognition" (Ramsey forthcoming, MS 11). Nevertheless, philosophical interest in the problem has renewed in the present century with several attempts to describe "the mark of the cognitive" (beginning with Adams and Aizawa 2001). These "marks" usually take the form of dichotomous criteria for COGNITION ${ }^{1}$-necessary and/or sufficient conditions for categorizing items as cognitive or non-cognitive-that serve to justify some set of theoretical perspectives and undermine others. However, none of these proposals has proven popular. More recently, some philosophers have turned their attention from "direct assault" on the problem (Aizawa forthcoming, MS 3) toward more modest, substantive questions about the scientific concept COGNITION, such as whether cognition is identical to a kind of behavior (Aizawa forthcoming; Shapiro 2013), ${ }^{2}$ or whether cognition is representational as a matter of conceptual fact rather than as a matter of empirical fact (Ramsey forthcoming).

I have two aims in this paper. The first is to articulate the problem of cognition more explicitly than has been done before, inter alia describing the stakes of the problem, in order to combat the common attitude that the problem of cognition is not worth addressing. Specifically, I will describe four ends that would be served by a characterization of cognition. In doing so, I assess whether the dominant strategy for answering the problem of cognition-that of seeking

${ }^{1}$ Throughout, I employ the convention of small capitalization to indicate reference to concepts. Cognition is a natural phenomenon, "cognition" is a word, and COGNITION is a concept.

${ }^{2}$ It seems that, excepting some enactivists, there is a consensus that cognition is not in general to be identified with a kind of behavior (op. cit.), at least when speaking carefully. Given the significant minority status of the view that cognition is behavior, its failure to be taken up in careful theoretical discussion outside of philosophy, and its failure to have a discernible effect on empirical research independently of other enactivist claims, I will not consider it in this paper. I thank an anonymous reviewer for vigorously pressing me on this point. 
a dichotomous categorization that justifies certain theoretical perspectives over rival perspectives-is likely to accomplish those ends. I am not sanguine about its prospects. My second aim is to describe an alternative criterion of success for understanding the scientific concept of cognition - what I call ecumenical extensional adequacy. An ecumenically adequate account of COGNITION represents cases that engender disagreement as controversial, rather than settling whether they belong to the extension of COGNITION. I argue that an ecumenical account is more likely than the dominant strategy to serve more of the ends that motivate the problem of cognition. I do not offer a solution to the problem of cognition or a "mark of the cognitive" in this paper; the approach I advocate is so thoroughly absent from the contemporary discussion that it merits a defense independently of any specific ecumenically adequate solution. What I do offer is a clarification of what is at stake in the problem of cognition, and the articulation of an approach to resolving it that has been overlooked so far.

I will begin by rehearsing some historical considerations that have recently made the problem of cognition more urgent. Extant treatments of the problem of cognition are usually motivated by a desire to resolve open questions about the nature of cognition that have become pressing since the 1980s. The fact of widespread expert disagreement about the nature and extension of cognition produces practical demands for policing the boundaries of the cognitive scientific enterprise. I will also argue, however, that the scientific concept of cognition is maturing. An explication of COGNITION might aim to characterize this maturation-inprogress, rather than to predict its course. In the second half of the paper, I describe an alternative approach, the ecumenical strategy, on which open disagreements are represented as disagreements rather than resolved. This strategy allows us to articulate the strands of ongoing conceptual change in cognitive science, and to better serve philosophers and other noncognitive scientists. I conclude that the ecumenical strategy should be pursued, rather than neglected as it is now.

\section{The Cognition Border Wars}

The problem of cognition is not a matter of merely academic curiosity. It is sometimes observed that biologists are not particularly impeded for want of a definition of LIFE (Cleland 2012; Machery 2012), and it is therefore unclear why one should want an explication of COGNITION. ${ }^{3}$ I will say at the outset that I agree that biologists can do biology without a definition of LIFE, and that much of cognitive science can likewise proceed unimpeded without an explication of the scientific concept of cognition. On this matter I am in the company of

\footnotetext{
${ }^{3}$ I adopt the term "explication" or "conceptual explication" in place of "conceptual analysis" because it seems to have fewer controversial Kantian connotations regarding analyticity.
} 
Andy Clark (2008, 239n3), Robert Rupert (2013, 42-43), Ken Aizawa (forthcoming, MS 1-3), and many others. Nevertheless the problem of cognition is pressing, and more pressing than corresponding questions in biology, for several reasons. First, unlike definitions of LIFE for biology, explications of COGNITION are taken to settle criteria of demarcation for cognitive science. Biologists study viruses even though on many proposed definitions they are not considered living, and they would study some non-homeostatic processes even if biological systems turned out to be necessarily homeostatic. But the claims that "groups of people are not themselves cognitive systems" or that "tool-use is not a cognitive process" are taken to have the consequence that cognitive scientists should not expend effort modeling mechanisms that extend outside of people’s heads (Adams and Aizawa 2001, esp. 61f; Rupert 2004, esp. 425). A second reason, which compounds the urgency of the first, is that contemporary cognitive scientists disagree strongly about the boundaries of cognition, and therefore about the boundaries of cognitive science.

Recent interest in the problem of cognition was inspired in large part by what might be called the cognition border wars, and in particular by controversy over the hypothesis of extended cognition (Clark and Chalmers 1998) which holds that cognitive processes are constituted in part by processes that extend outside of the brain and the body. However, the hypothesis of extended cognition is merely the straw that broke the camel's back. It is a latecomer in a host of (what I will call) anti-classical perspectives in cognitive science that began gathering support in the 1980s, following the connectionist challenge to classical cognitive science. Some of these perspectives, like connectionism and dynamicism (Rumelhart 1989; Thelen and Smith 1994; van Gelder 1998), promote non-classical strategies for modeling cognitive processes. Other anti-classical perspectives have unintuitive consequences about where cognition can be found (so they cover all the ground that Chemero and Silberstein 2008 identify as the "new philosophy of mind"). Arguments that machines can exhibit genuine cognition are as old as classical cognitive science (Turing 1950; Putnam 1967), but anti-classical partisans are apt to recognize cognition in a host of other contexts. Proponents of embodied cognition argue that cognitive processes extend out of the brain and into the non-neural tissues of the body (Gibbs 2005; Chemero 2009; Clark 1997; Varela et al. 1991). Proponents of group and social cognition argue that the coordinated activity of multiple corporeal agents sometimes counts as a distinctive kind of cognitive phenomenon (Hutchins 1995). Some researchers now hold that plants have cognitive processes (Trewavas 2003; Calvo Garzón 2007). Enactivists hold that cognition consists in activity on the part of a whole organism, and not in the manipulation of representations or information (Varela et al. 1991; Hurley 1998; Noë 2006), and sometimes that all living organisms-including microbes-engage in cognitive activity (Stewart 1996; van Duijn et al. 2006; Thompson 2010). These anti-classical perspectives are all controversial-none 
is generally accepted, but each is defended by cognitive scientists from a range of disciplinary backgrounds

Although philosophers have often been the most systematic exponents and critics of the anti-classical perspectives, the debates of the border wars turn on bodies of empirical and formal research in the other component disciplines of cognitive science (see e.g. Clark 1997, 2008; Rowlands 2010 for this style of argumentation). These perspectives are each embraced by groups of researchers of many backgrounds, and inform cognitive scientific research in several disciplines. For example, enactivism was spearheaded by biologists and found a firm proponent in the psychologist Eleanor Rosch. The ecological approach was first articulated by psychologist J.J. Gibson. Proponents of embodied cognition and its value to empirical work are found throughout psychology (see e.g. Gibbs 2005 for discussion) and computer science, especially in robotics (Brooks 1991; Webb 1994). So the border wars should not be dismissed as excessive fuss about the overly bold claims of iconoclastic philosophers.

The result is that there are now open questions in cognitive science where no one (or very few) saw open questions up until the 1980s: ${ }^{4}$ Might cognition involve non-representational processes? Are some properties of muscles, or the structure of the body, parts of cognitive mechanisms? Can artifacts or the structure of the environment be parts of cognitive mechanisms? Do plants have cognitive processes? Microbes? I shall refer to this state of affairs, that so many fundamental questions about the nature and extension of cognition remain controversial, as the fact of widespread expert disagreement. Shortly after Andy Clark and David Chalmers argued that cognitive processes are realized by structures outside of the body, Fred Adams and Ken Aizawa argued for a "mark of the cognitive": a dichotomous criterion for COGNITION meant to exclude the possibility of several of these anti-classical perspectives. They have been joined by others (notably Rupert 2009; Rowlands 2010; Buckner 2015; Adams and Garrison 2013) describing rival accounts. These criteria aim to demarcate which phenomena are cognitive ones and which are not; they do not aim to be models of the various causes, mechanisms, or courses of particular cognitive phenomena (cf. Wakefield's rough distinction between "concept" and "theory"; 1992, 374).

Thus, the first reason to care about characterizing cognition correctly is to settle the open questions inspired by the border wars. Sven Walter (2010) and Mark Rowlands (2009), for

\footnotetext{
${ }^{4}$ The history is of course complicated. Some border war controversies have predecessors. The characterization by scientists of "unconscious" processes by analogy to highfalutin cognitive processes like inference goes back at least as far as the 19th century, e.g. Helmholtz' (1867) "unconscious inference." Scientific consideration of microbe cognition goes back at least as far as early enactivism among Chilean biologists in the 1970s (Maturana and Varela 1980, originally published in 1970). However, the mainstreaming (or re-adoption) of these perspectives has accelerated since the 1980s, when the border wars began.
} 
example, argue that questions about extended cognition cannot be answered until we know the "mark of the cognitive." Normally, these questions are taken to have normative consequences for the way cognitive science is done. If cognitive science just is the study of cognition, then clarity about the extension of COGNITION delimits the proper scope of the cognitive scientific enterprise (Rupert 2004). That is to say, cognitive science is the study of cognition, and the extension of COGNITION determines demarcation criteria for cognitive science. ${ }^{5}$ Without a positive characterization of COGNITION, it is feared that the practice of cognitive science might be wildly misguided. We might be studying the wrong object, or studying it the wrong way. Addressing these concerns appears to be a primary dialectic goal of most of the present literature on the "mark of the cognitive"-Adams and Aizawa (2001, 2008) conclude based on their proposed "mark of the cognitive" that many anti-classical research programs, including those into cases of putatively extended and social cognition, are misguided. Rowlands (2009, 2010), on the other hand, concludes based on his alternative "mark" that certain anti-classical research programs are legitimate, including those concerning extended cognition.

If the correct explication of COGNITION can contribute to disputes about the legitimacy of various research programs then the problem of cognition is not only a matter of scientific but also of social significance. After all, cognitive science research is often funded by national funding bodies with limited resources. The funding of misguided research programs unjustifiably draws funding away from legitimate research. For example, if plant cognition is not real, we should not fund research about it. Or consider the recent trend of dedicating substantial resources toward brain-centered research projects (such as the BRAIN Initiative, the Human Connectome Project, and Henry Markram's Human Brain Project) and away from more traditionally "cognitive" behavioral or formal work. It behooves us to be as clear as we can about the nature of cognition, and therefore the value of various strains in cognitive science, in order to reflect on what, if anything, we are missing out on due to this trend. Thus, although William Ramsey asks for a rationale "beyond turf wars and funding issues" that justifies interest in the problem of cognition (forthcoming, MS 11), I am inclined to think that that alone would be enough. After all, the products of philosophical effort-arguments, explanations, accounts, conceptual analyses, distinctions, and so on-are not merely attempts to limn the ultimate structure of reality. They are devices for thinking clearly and justifying one's claims, not just for

\footnotetext{
${ }^{5}$ Ramsey (forthcoming) also claims that cognitive science should be understood as the study of cognition, whatever cognition is, but denies that any speculative "mark of the cognitive" should limit our inquiry. I am inclined to agree that it should not, as will become clearer, but disagree with Ramsey that there is therefore no important end served by trying to resolve the problem of cognition. However, cf. Rupert (2013) for a dissenting view, that cognitive science is not aptly characterized as the study of cognition; his dissent is based on the premises that in order for that description to be a happy one cognition must be a well-behaved natural kind, and that cognition is not a natural kind.
} 
their original expositors but for other inquirers. Philosophers of cognitive science are part of the scientific community, and if our work has edifying practical consequences for the study of cognition then so much the better for all of us.

Nevertheless, I contend that there indeed are reasons beyond turf wars and funding issues to care about the problem of cognition. Cognitive scientists are engaged in theoretical disputes about which conception of cognition is best. Consider that value theorists might engage in disputes over how to understand JUSTICE or AGENCY, and feminists might disagree about how we should understand gender terms like WOMAN; it is inappropriate to observe that various parties to these disputes mean different things by their words and leave it at that. Matters of social justice depend on understanding these concepts correctly, and the disputes are not mere confusions but precisely disputes about how one should use an expression or categorize phenomena, supposing of course that the expression has a regulatory function concerning how to think about politics, action, social justice, \&c. The border wars may not be a matter of social justice, but they are a matter of scientific importance, and should be seen inter alia as disputes over what we should mean by "cognitive," supposing it has consequences regarding the demarcation of the cognitive sciences and makes explicit some scientific gains of recent decades. Put another way, the cognition border wars are an instance of what is sometimes lately called "conceptual ethics" (Burgess and Plunkett 2013a, 2013b), or what Sally Haslanger calls an "analytical approach" (2000).

The dominant strategy for resolving the problem of cognition is exemplified, above all, in positive proposals for a "mark of the cognitive" like those advocated by Adams and Aizawa (2001, 2008), Rowlands (2009, 2010), Buckner (2015), and Adams and Garrison (2013). The dominant strategy is meant to resolve the problem of cognition by addressing the boundarypolicing function, and it accomplishes this by aiming for a dichotomous categorization of items into those that are cognitive and those that are not cognitive. Both this aim and this means bear more precise description. I will discuss each in turn, and articulate the case for considering an alternative strategy for resolving the problem of cognition. First, however, I will consider some benefits other than boundary-policing that we might reap by providing an explication of the scientific concept COGNITION.

\section{Other Reasons to Care about the Problem of Cognition}

To reiterate, I am not claiming that we need a "mark of the cognitive" in order to do cognitive science at all. However, there are reasons we might want to have a characterization of cognition ready to hand. There are at least four functions that a solution to the problem of cognition could serve for inquirers. Above I described the boundary-policing function that has been the focus 
of contributors to the literature on the "mark of the cognitive" in the present century. It is worth underlining that the problem of cognition and the open questions of the border wars are not identical. The problem of cognition is the lack of any widely-accepted positive characterization of cognition despite a felt need for such a characterization. The border wars are a collection of unresolved theoretical and methodological disputes in cognitive science. The border wars lend urgency and focus to the problem, but there are benefits apart from resolving the border wars that we might enjoy if we had a positive characterization of cognition. Namely, there are epistemological, public relations, and metaphilosophical functions that a solution to the problem of cognition could serve. I will motivate these remaining three functions with arguments that the scientific concept COGNITION is changing, and that this change is welldescribed as progress.

\subsection{The concept COGNITION is changing}

Perhaps the clearest example of conceptual change is that cognitive scientists now routinely distinguish between two fairly distinct senses of "cognition." A highfalutin kind of cognition, sometimes called "higher cognition," is roughly synonymous with "rational thought" and figures in expressions like "cognitive therapy" and "cognitive control." Cognition in this sense is normally understood in contrast to phenomena such as perception and affect. Prinz (2004), for example, suggests a working definition of COGNITION meant explicitly to contrast with perception. More recently, Nico Orlandi $(2014,6 f)$ discusses the perception-exclusive notion of cognition. The highfalutin sense of "cognition" is closely related to the traditional sense of "cognition" inherited from Latin. In the late 2oth century, though, scientists began using the word "cognition" to refer to a more inclusive category of phenomena that contains all the proper objects of study for cognitive science. There is no controversy that this category includes un-thoughtlike phenomena such as perception, affect, motivation, and motor control. (The distinction between two senses of "cognition" is drawn explicitly in Greene et al. 2004, 389; Rowlands 2009, 7.) "Cognition" in this inclusive sense is a scientific neologism of recent decades. Since highfalutin cognition is a more restrictive phenomenon, understood explicitly in contrast to phenomena like perception and affect that are generally agreed to be proper objects of cognitive scientific study, the problem of cognition cannot be about the extension of highfalutin cognition. The explicit restriction of "highfalutin cognition" as a descriptor for e.g. nonperceptual contexts implies that it cannot serve the boundary-policing function. However, its sincere use in scientific contexts should incline us to think that it is a scientific concept. That is to say, the contrast is not between a pretheoretic (highfalutin) and a scientific (inclusive) notion of cognition, but rather between two notions used simultaneously by scientists. These senses 
are nevertheless distinguishable in terms of their consequences of application-to claim that a process is cognitive in the highfalutin sense implies inter alia that it is not perceptual or not affective, though it may still fall within the purview of cognitive science. To claim that a process is cognitive in the inclusive sense implies inter alia that it is in the proper domain of cognitive scientific inquiry.

\subsection{The conceptual change concerning COGNITION is progress}

The distinction between highfalutin and inclusive cognition is evidence of the conceptual change already accomplished in cognitive science; it would have been bizarre in the 1920 s to refer to sensation or emotion as "cognitive" phenomena, rather than as psychological phenomena more generally. But the border wars are inter alia about whether inclusive cognition encompasses even more natural phenomena than perception, affect, and motor control. The open questions of the border wars were undreamt of or safely ignored before the 1980 s, but are matters of legitimate controversy now. The reason that the questions of the border wars have become pressing to cognitive scientists is that their unintuitive conclusions have been motivated by argument and evidence. Advocacy for embodied and situated cognition, in particular, has been conducted with arguments that draw on intuition-twisting empirical studies (see e.g. Clark 1997; Gallagher 2005; Gibbs 2005; Rowlands 2010 for some book-length collections of such arguments). As a result, it has become increasingly common for empirical work to embrace other perspectives like situated cognition and Gibson's ecological psychology (Robbins and Aydede 2008), though other anti-classical perspectives like enactivism and dynamicism remain quite unpopular.

Briefly then, here is an argument for the claim that COGNITION is undergoing conceptual progress. The concept is certainly changing. This is evidenced, first of all, in the relatively recent conceptualization of perception, affect, \&c. as kinds of cognitive phenomena. Second of all, the border wars raise open questions about the nature of cognition that were mostly considered either absurd or radical before the 1980s. That these questions have meanwhile become legitimate implies that cognitive scientists think of their object of inquiry in a new way. Hence, the norms for using the concept COGNITION have changed since the cognitive revolution, and they continue to be negotiated in the border wars. Furthermore, it is reasonable to say of such changes that they are progressive if the changes are motivated in substantial part by efforts to respond to evidence, or more generally to describe the world well in light of recalcitrant experience. And there is evidence that changes in the scientific concept of cognition have been motivated by such efforts. 
One might tell a potted history like this: at the beginning of the cognitive revolution many expected personal-level cognitive processes to resemble folk psychological kinds in their categories and dynamics. As cognitive science matured in the 1970s and '8os this expectation was belied by empirical results like those that fractured folk-psychological kinds like MEMORY into a multiplicity of cognitive kinds, e.g. into sensory, short-term, and long-term memory (Atkinson and Shiffrin 1968), or into episodic and semantic memory (Tulving 1972). Research into biases and heuristics in judgment and decision-making, like that associated with Amos Tversky and Daniel Kahneman (Tversky and Kahneman 1974), upset rationalistic conceptions of personal-level cognitive dynamics. It is easy to see the AI Winter of 1970s and the sudden popularity of mental eliminativism in the early 1980s (Churchland 1981; Stich 1983) as consequences of results like these. On the other hand, many subpersonal processes have turned out to be unexpectedly context-sensitive and subject to top-down modulation (see e.g. Clark 2001). In short, the distinction between highfalutin cognitive processes and less fancy cognitive processes became less clear, and sometime in that period cognitive scientists began commonly using "cognition" in its inclusive sense. The anti-classical views of border wars are motivated by appeal to such lost contrasts. This reasoning is apparent, for example, in Edwin Hutchins' defense of distributed cognition (1995), Clark and Chalmers' appeal to parity in defending extended cognition, and Francisco Calvo Garzón's appeal to representation-in-absence to defend plant cognition (2007).

Hence, the conceptual change driven by the border wars is well-characterized as progressive, rather than as arbitrary, or as a reflection of merely notational trends, or as conceptual drift. The sense of "progress" here is not that of closer approximation to the truth, whatever the truth might be, but that of responsiveness to evidence, whether in the right or wrong direction. I contend, therefore, that we should understand the border wars as evidence of ongoing conceptual progress among cognitive scientists concerning their understanding of the object of their inquiry. That is, the open questions of the border wars are, in part, questions about how scientists should understand and ascribe the concept COGNITION, and contributions to the border wars are inter alia attempts to predict and influence the course of conceptual change.

Conceptual progression of this sort is a cornerstone of science. Much of the most interesting scientific innovation is conceptual innovation. Our science is more advanced than Aristotle's not because he simply didn't examine the world carefully enough, but among other things because we have learned better vocabulary in which to couch our questions and theories. Contemporary scientific concepts like GENE and TEMPERATURE are hard-won fruits of scientific inquiry (Griffiths and Stotz 2006; Chang 2008), and their careers of development pushed against pretheoretic intuitions (Francis Bacon, for example, thought that a scientific 
theory of heat must identify what is common between such substances as fire, warm baths, sunshine, wine, and wool; Novum Organum, II.XI). If the border wars are evidence of conceptual progression concerning COGNITION, then we are presently living through a moment of major conceptual change in the scientific understanding of the mind. New research questions and theoretical trends in cognitive science reflect what we as a scientific community have learned about cognition from decades of doing cognitive science. For example, the notion of inclusive cognition has proved useful because whatever important dissimilarities there may be between, say, rational judgment (highfalutin cognition) and edge-detection in V1, there are some significant continuities revealed by cognitive scientific results. That these continuities are important is generally agreed upon notwithstanding disagreements concerning the nature of these continuities-whether they are information-processing interactions, for example, or common recruitment by linguistic capacities.

That counterintuitive claims are embraced by proponents of anti-classical research traditions is a symptom (though not a criterion) of conceptual maturation. However, the lack of any agreement about how to resolve the problem of cognition implies that whatever we have learned has not been made very explicit, and that the border wars remain controversial implies that cognitive scientists disagree on how to conceive of their object of study. We may hope that a successful explication of COGNITION would make some of that knowledge more explicit, in the way contemporary treatments of TEMPERATURE or GENE make explicit what we have learned about heat and genetics by doing physics and biology. And since cognitive scientists disagree about how the concept COGNITION is to be applied, we might hope furthermore that an explication would make explicit which if any commitments are shared among cognitive scientists, and which commitments are not shared. Thus, in addition to the boundary policing function described in the previous section, there is a second, epistemological, reason to address the problem of cognition. An explication of COGNITION should make explicit what cognitive scientists have learned, but not yet clearly articulated, about their object of study.

\subsection{Relations to the public and to philosophy}

I said earlier that the problem of cognition is that there is no clear account of how cognitive scientists in general understand cognition, though there is a felt need for such an account. If this is what the problem of cognition is, then demarcation is not the only-or even the most interesting-purpose of addressing the problem. Since the scientific concept of cognition is undergoing change (and, indeed, progress), there are other practical and theoretical problems that we might hope to address by resolving it. In particular, if an explication of COGNITION can illuminate what we have learned about cognition by doing cognitive science, and if it can 
put certain counterintuitive claims about the nature of cognition in perspective, then it may also serve a public relations function and a metaphilosophical function. These two functions are best served by an approach that seeks primarily to make explicit the as-yet implicit knowledge that cognitive scientists have accumulated.

Regarding public relations, the inclusive concept of cognition is poorly understood by those who do not work in the cognitive sciences. Novice students and non-experts often struggle to understand why something called cognitive science is concerned with phenomena like perception, emotion, or dreaming. Furthermore, the controversies of the border wars, over e.g. extended cognition or plant cognition, are often considered absurd by laypeople and some philosophers, although they are taken seriously by many cognitive scientists. Currently, the only way to acquire a basic facility with the scientific concept of cognition seems to be to study cognitive science for a period of months or years. A successful explication of COGNITION that aims to make explicit the implicit commitments involved in scientific work would, even if only in the form of a slogan, make the nature of cognition and the enterprise of cognitive science more accessible to non-specialists.

Finally, increased clarity about the nature of cognition, at least as conceived in the scientific image, has the potential to shed light on other recalcitrant philosophical problems. If, as is commonly thought, mental states are a subcategory of cognitive phenomena, then solutions to the problem of cognition stand to contribute to disputes about the place of minds in nature. Cognitive phenomena are also frequently at the center of controversies about scientific reductionism, scientific abstraction, multiple realizability, and the nature of computation and representation in the cognitive sciences. An explication of COGNITION would have the metaphilosophical benefit of serving as a reliable resource for appeal regarding arguments in these literatures. At the moment, some form of Putnam- or Lewis-style functionalism usually serves as such a resource for appeal (Eliasmith 2002; Sprevak 2009; Chalmers 2011), despite widespread misgivings about functionalism's adequacy for this purpose (see Block 1980 for a review of classic, and still mostly unanswered, objections). However, if science is to be a guide to addressing these philosophical questions, we are safest in using as a resource for appeal a characterization of cognition that makes explicit the implicit commitments of scientists, but does not incorporate speculation about the answers to questions that are, as far as cognitive scientists are concerned, empirically open.

So there are four aspirational benefits of a successful characterization of cognition: First, it would have normative practical implications for cognitive science, specifically on the legitimacy of controversial research programs. Second, it would reflect what contemporary cognitive science knows (or perhaps merely believes) about cognition in general. Third, if compact it would facilitate clearer communication across disciplines and to non-experts, and 
finally it would serve as a flexible resource for appeal regarding other philosophical topics of interest. Cognitive science and its philosophy will not founder without a positive characterization of cognition, but a promising explication would be a significant boon to the field if it achieved some of these benefits.

\subsection{A remark about analyticity}

These four ends should also serve to dispel a concern expressed by Robert Wilson, who worries that the demand for an explication of COGNITION is unbecoming for

philosophers who take one of the chief lessons of the failure of logical positivism in the philosophy of science, the collapse of the analytic-synthetic distinction along Quinean lines in the same, and the limitations of conceptual analysis to be a deep suspicion of the search for such principles. (2010)

That is, Wilson worries that many attempts to produce a conceptual explication of COGNITION will be inconsistent with a thoroughgoing rejection of the analytic-synthetic distinction. I believe this worry can be overcome. First of all, since the explication demanded is one that draws explicitly upon empirical knowledge, and whose adequacy depends on its responsiveness to that knowledge, it does not presuppose a strong distinction between analytic or meaning-constitutive claims and synthetic or extra-conceptual claims. Put another way, the distinction between explication and theory is not absolute, nor do explications and theories rely on clearly distinguishable bodies of evidence. Furthermore, by acknowledging the four functions above, the problem of cognition can be distanced from a demand for faithfulness to something called a "meaning." Instead, an explication that resolves the problem of cognition can be judged by its potential to serve these four ends. Even if no single explication can simultaneously serve all four of these functions, any proposed explication of COGNITION might be measured against its potential to yield some combination of these four benefits.

\section{Sectarian vs. Ecumenical Extensional Adequacy}

Some philosophical approaches are promising ones for achieving these four benefits, and some are not. For example, it should be clear that an account of cognition along old-fashioned lines, that makes judgment or rational thought central, is not what is called for in this context. The

highfalutin notion of cognition is not the one that serves to demarcate the bounds of cognitive science, nor the one whose usage encodes the most interesting conceptual maturation, nor is it 
the one that eludes non-specialists or is needed as a resource for appeal regarding philosophical discussions that take the scientific conception of minds to be highly germane. The intended object of description here is the novel scientific concept of inclusive cognition wrought by cognitive scientists-the one with the surprising consequence that it makes the border wars of the 1980 os and '9os intelligible. This much is agreed upon by the major contributors to what I have called the problem of cognition. Some of them construe their proposals as empirical hypotheses (e.g. Adams and Aizawa 2001; Rupert 2004; Adams and Garrison 2013; Buckner 2015). Some justify their proposals by appealing to the structure of contemporary theories (e.g. Rowlands 2009). All agree that contemporary or future cognitive science is the measure of the "mark of the cognitive."

William Ramsey is only an apparent exception. He argues that we should allow our "intuitive, pre-theoretical image of the mind" guide us in roughly demarcating the subject matter of cognitive science. This pre-theoretical image is furthermore "in all likelihood a cluster concept with fuzzy boundaries, with some prototypical processes in the center and more obscure or atypical processes on the periphery" (Ramsey forthcoming, MS 12). But since the scientific concept of cognition is changing, as I argued above, Ramsey's strategy faces a dilemma. Either the "pre-theoretical" conception that guides our characterization should be insensitive to ongoing conceptual change, or it should accommodate that change. If our pre-theoretical conception is insensitive to conceptual development in cognitive science, this strategy would require us to backtrack in ways that may obscure implicit insights won over the decades, rather than illuminating them. For example, it would plausibly deny that perception or motivation are cognitive processes (this is almost certainly not a view that Ramsey actually supports). If our pre-theoretical conception is sensitive to conceptual developments in the science, then Ramsey does not really disagree with the guideline that contemporary or future cognitive science is the measure of the "mark of the cognitive," and it is at best awkward to describe our conception of cognition as "pre-theoretical," even if it descended from such a notion.

Extant "marks of the cognitive" also agree on a general strategy for addressing the problem of cognition. This dominant strategy has two components. First, each "mark" pursues a dichotomous ideal according to which the ideal "mark" would categorize everything in the world as either cognitive or non-cognitive. I will discuss the dichotomous ideal in the next section. The second general feature of the dominant strategy is to respond to the fact of widespread expert disagreement by picking sides in the border wars. That is, instead of somehow accommodating disagreement in a characterization of cognition, they explicate COGNITION in a manner that is agreeable to some and disagreeable to others. Call this conception of success sectarian extensional adequacy, and its pursuit the sectarian strategy of 
conceptual explication. All of the extant accounts pursue the sectarian strategy. ${ }^{6}$ Traditional conceptual analysis or explication aims inter alia to render the extensions of concepts more precise than in actual judgments (e.g. Quine 1960, 258-262). This is also what is demanded by sectarian adequacy; sectarian explications embrace revisionary consequences and serve to express, vindicate, or undermine the theoretical assumptions of various research programs.

However, the problem of cognition is unlike many other cases of scientific conceptual explication. Many other explicative projects aim to be adequate to consensual judgmentsthose drawing universal (or near-universal) assent from experts. Appeal to consensual judgments is frequently invoked as the adequacy criterion justifying contingent identifications (Smart 1959) such as the identity between water and $\mathrm{H}_{2} \mathrm{O}$, lightning and atmospheric electrostatic discharge, or gold and the chemical element denoted by the symbol Au. This is also the criterion by which explications of more controversial concepts like DISEASE are usually measured (e.g. Boorse 1977; Wakefield 1992; Lilienfeld and Marino 1995), and by which many proposed definitions of LIFE have failed (Cleland 2012). However, because of the fact of widespread disagreement, this explicative strategy is unavailable in the case of COGNITION. Consensual judgments cannot be the arbiter of competing "marks of the cognitive" because there are no consensual judgments concerning the controversial cases raised in the border wars, and the "marks" are invoked in order to adjudicate those cases contrary to common expert judgments. Rather, the extant "marks" are defended by appeal to various abstract considerations that are themselves contentious. For example, claims about inductively successful explanatory strategies (Adams and Aizawa, Buckner), the metaphysics of representation (Adams and Aizawa, Rowlands), the metaphysics of proper functions (Rowlands), or controversial claims about the metaphysics of reasons for action (Adams and Garrison).

There is nothing inherently objectionable about this strategy; it is of a piece with other theoretical activity. Nevertheless, since candidate "marks of the cognitive" are more speculative than many other scientific conceptual explications, they have a more contentious relationship to their respective science. Because they take sides in unresolved theoretical disputes (and rely on contentious abstract considerations rather than widely-endorsed results), they effectively make bets about the future-either about what we will discover about cognition, or about how cognitive scientists will decide to describe and explain cognitive phenomena. This fact limits their potential for achieving the four benefits described above. With respect to boundary-

\footnotetext{
${ }^{6}$ Even Buckner, whose goal is to demarcate cognition from association rather than to take a side in the border wars per se, takes his account to have alarming revisionary consequences, e.g. that cases of associative learning, such as taste aversion, are not cognitive phenomena $(2015,315)$. This consequence may be appropriate for highfalutin cognition, but is alarming for inclusive cognition.
} 
policing, the limitations are modest and widely-acknowledged: sectarian criteria are controversial. With respect to the other benefits, though, their limitations are more pernicious. The epistemological benefit was that an explication of COGNITION might make explicit the new ways that cognitive scientists think about their object of study, such that the disputes and counterintuitive claims of the border wars are rendered comprehensible. However, in embracing speculative hypotheses, sectarian proposals mask matters on which cognitive science is still ignorant by failing to distinguish what the scientific community agrees on and what they have yet to resolve. The resultant criteria mix the conceptual developments of recent decades with conjectures about how those developments might continue. The conjectures are informed, to be sure, and plausible sectarian explications do articulate the theoretical commitments of a subset border war partisans, but they do not reflect the current state of the science. Furthermore, since sectarian explications downplay rather than acknowledge our current ignorance, they are imperfect instruments for pedagogy and public communication, thus compromising their aptness for accomplishing the third benefit. Finally, the speculative aspect of sectarian criteria also undermines their value as secure resources for appeal by philosophers whose arguments depend on premises articulating the scientific conception of the mind. This worry may not be pressing in literatures whose readers are well-versed in border war controversies, but is a significant liability in many literatures where these controversies are not so familiar.

The latter three benefits are better served by an alternative conception of success: ecumenical extensional adequacy. Whereas sectarian explications are adequate to the judgments of some but not all partisans in the border wars, an explication is ecumenically adequate if it accurately models the state of disagreement between experts (i.e. cognitive scientists). The aim is to account for the conflicting ascriptive practices of scientists, rather than to correct them. An ecumenically adequate explication accomplishes this by classifying phenomena not only as cognitive or non-cognitive, but as phenomena that are generally agreed 
a

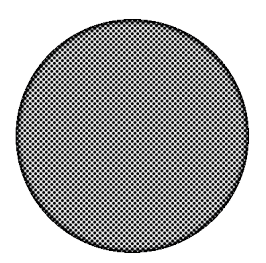

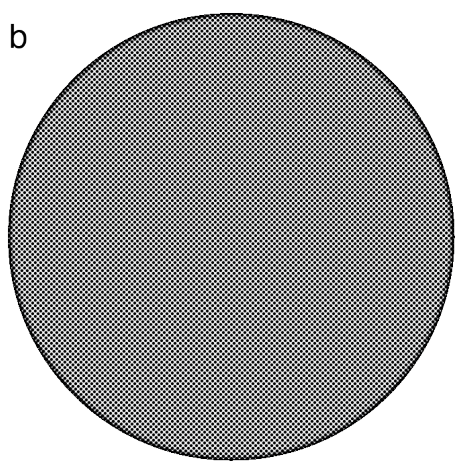

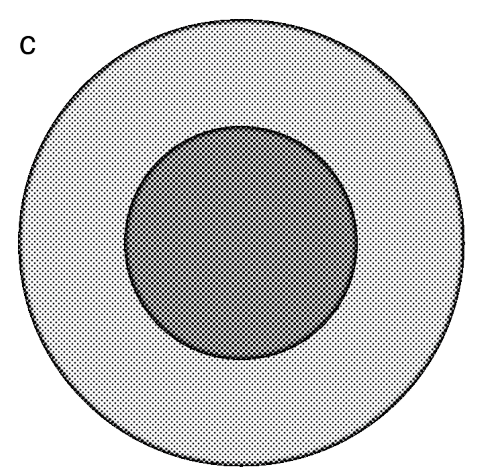

Fig. 1 Venn diagrams representing classical and ecumenical extensions. a: A conservative classical extension (small circle). b: A liberal classical extension (large circle). c: An ecumenical extension (large and small concentric circles).

to be cognitive, phenomena that are generally agreed not to be cognitive, and phenomena that engender disagreement regarding whether they are cognitive. ${ }^{7}$

In order for an explication to be ecumenically extensionally adequate, it must produce a non-classical extension. A classical extension, represented by a single classical set, includes some items as members and excludes all others without differentiating any grades or variations in its members. Everything in the world is either in a classical extension, or it is not. By contrast, an ecumenically adequate criterion must have an extension with at least two grades, corresponding to degrees of agreement about whether items belong in the extension of a concept (Fig. 1). In Fig. 1c, an ecumenical set with two grades of membership is modeled as a set and a subset, represented by a Venn diagram consisting of two concentric circles. The elements belonging to the subset are paradigmatically cognitive items, such as neural memory processes and visual processes. The superset contains those items as well as controversially cognitive items such as extended cognitive processes, plant cognitive processes, and robot cognitive processes. The consensual non-cases of cognition belong to neither circle. Thus the controversial cases are represented by the set of members of the superset that are not also members of the subset. ${ }^{8}$

\footnotetext{
${ }^{7}$ As Adam Marushak says regarding contextualist approaches in philosophy of language (and echoing Lewis):"If the house is going to shake, you want the foundations to sway, too" (Marushak, personal communication; cf. Lewis 1973, 92).

${ }^{8}$ A scholar of journalism or political science might be reminded here of Daniel C. Hallin's characterization of OBJECTIVITY in media coverage (1986). Hallin suggests that a journalist's claim may fall into either of the "sphere of consensus," the "sphere of legitimate controversy," or the "sphere of
} 
To be clear, what I've described is a conception of adequacy, not a modeling strategy that fulfills that conception. My suggestion is not that we merely catalogue facts about the variety of expert judgments concerning cognition, but that we aim for an account that explains those judgments, including the conflict and variance between them, rather than a criterion that vindicates only a privileged subset of those judgments. An explication is not identical to its standard of adequacy, and an ecumenically adequate explication is no more a mere catalogue of sociological facts than a sectarian explication is a mere catalogue of natural facts. For either standard of adequacy one might explicate a concept merely by listing every possible instance of cognition, but this is a limiting case.

Plausibly, an ecumenically adequate explication of cognition will consist of some criterion (substantially more compact than a list of cases) that articulates features of cognition and explicitly marks some features as shared between conceptions of cognition, and marks others as objects of ongoing dispute. For example, there is ongoing dispute over how to understand the notion of REPRESENTATION as it features in cognitive science, and many extant disagreements about the nature and extension of cognition are cashed out as disagreements about the nature and extension of natural representation. Thus, Calvo Garzón argues that plants have cognitive processes because they represent their environment (2007), whereas Ramsey argues that plants do not have cognitive processes because nothing plants do is worth calling "representation" (2007). An ecumenically adequate explication of COGNITION may invoke the notion of REPRESENTATION without answering such questions, thus elucidating the commitments that are common and divergent between Calvo Garzón and Ramsey (though Ramsey [forthcoming] argues that an explication of COGNITION should not appeal to the notion of REPRESENTATION). And there is some precedent for such an approach in philosophy-the justified-true-belief account of knowledge might be understood to work this way, drawing broad assent (at least before the publication of Gettier's 1963 paper) despite disagreement over the proper understanding of JUSTIFIED and its other component expressions.

\section{Dichotomous vs. Many-valued Categorization}

I claimed earlier that the dominant strategy has two features: a sectarian criterion of extensional adequacy, and a dichotomous ideal for a method of categorization according to which

deviance." These spheres describe the boundaries between claims that may be taken for granted by journalists, those that call for epistemic distancing or "balancing" evidence, and those that are generally considered unworthy of serious attention. My suggestion is that, in ecumenically characterizing cognition, we make similar distinctions regarding membership in the extension of COGNITION. 
everything in the world can be reckoned as cognitive or non-cognitive. Though no proponents of any extant "mark of the cognitive" claim to offer a necessary and sufficient criterion for being cognitive, they each seem to envision such a dichotomous criterion as the ultimate goal. Thus Adams, Aizawa, and Garrison offer various necessary conditions on cognition, dividing everything in the world into the non-cognitive and the possibly cognitive. Rowlands offers sufficient conditions, dividing the world into processes that are definitely cognitive and those that may or may not be. All of these authors consider their proposals incomplete because they do not settle the extension of COGNITION decisively. What they offer, then, is progress toward a dichotomous characterization of cognition. They do not offer ways of understanding a demarcation criterion that are alternatives to a dichotomous ideal.

Cameron Buckner's (2015) proposal is an exception, offering an attractive account on which COGNITION is a cluster concept in the style of Richard Boyd's homeostatic property clusters (Boyd 1991). However, Buckner's account amounts less to a traditional "mark of the cognitive" than to a field guide for inferring the existence of cognitive mechanisms based on clustered properties. Buckner anticipates that in the future we will discover a common kind of mechanism that exhibits the clustered properties, and that the description of this mechanism will offer the kind of classical clarity sought by other authors (2015, 324-325). Aizawa (2014) and Ramsey (forthcoming) have also suggested that COGNITION may be modeled as a cluster concept, but have not as yet articulated any positive accounts with a cluster structure.

Dichotomous ideals are appropriate for accounts that seek sectarian adequacy, especially when hedged in the ways that the extant "marks" have been hedged (e.g. by giving only necessary conditions). However, a dichotomous categorization cannot produce a non-classical extension of the sort demanded by ecumenical adequacy. Moreover, it is probable that a satisfactory explication of COGNITION will not take the form of a traditional characterization in terms of individually necessary and jointly sufficient conditions that accomplish a dichotomous categorization of everything in the world as either cognitive or non-cognitive. First of all, it is now commonly thought that few concepts submit to such characterizations (Ramsey 1992; Machery 2009, Chapter 3). Some concepts in physics may have such characterizations (though even this is not clear; see M. Wilson 2006 for extended discussion), but few important theoretical concepts in the biological or behavioral sciences do. Even extremely well-described concepts like NATURAL SELECTION resist traditional characterization (Godfrey-Smith 2009).

The pursuit of ecumenical extensional adequacy, which requires at least a three-fold categorization, requires forgoing classical clarity. The fact of widespread expert disagreement invites treatment in terms of more complex conceptual structures that come in degrees, or have sub-kinds, or something. The standard metaconceptual tools for modeling conceptual 
complexity are appeal to vagueness and ambiguity, but it is not clear that these tools are precisely what is called for, at least in their most straightforward forms.

First, vagueness in the manner of CLOUDY or SUNNY does not help to achieve ecumenical adequacy. Degrees of cloudiness can be compared according to a measure, and in a given context a standard can be set for being sufficiently cloudy to be worth calling "cloudy." (Notably, since necessary and sufficient conditions may employ vague predicates, a dichotomous characterizer may appeal to vagueness.) If COGNITION is vague in this sense, then items will exhibit degrees of cognitiveness. Thus, proponents of plant cognition could claim that plants are slightly cognitive, or sort of cognitive according to some measure, and that our standards of sufficient cognitiveness should be lowered to include them. However, whatever the merits of such a view, it does not reveal a straightforward path to an ecumenical account, since one can distinguish between the degree to which a property is exemplified and the degree to which judges are willing to ascribe a property. For example, it might be cloudier Tuesday than it was on Monday, and yet I might say it was not really cloudy on either day whereas Mariana insists it was cloudy both days. Monday and Tuesday vary with respect to their degree of cloudiness, and Mariana and I vary with respect to our degree of willingness to ascribe cloudiness. Simple vagueness refers to the former sort of variation, but ecumenical adequacy requires the latter sort of variation, since only the latter variation involves interpersonal disagreement. The vagueness of CLOUDY does not, by itself, provide an explanation or model for Mariana's and my differential willingness to ascribe cloudiness, and likewise for any explication of COGNITION. Furthermore, the case of COGNITION is complicated by the fact that variations in willingness to ascribe the concept are not monotonic-one may accept that there is extended cognition but not plant cognition, and vice versa. This is not to say that appeal to vagueness is inconsistent with an ecumenical strategy, but vagueness alone is insufficient to produce a many-valued extension of the sort demanded by ecumenical adequacy.

Similarly, "cognition" is not ambiguous in the blunt fashion of "bank" and "bank," in which the expressions concerned are merely homophonous. It is a natural instinct of the analytic philosopher to notice multiple standards for applying a word, and to distinguish between multiple senses in which the word might be used. Thus we might suppose that the enactivist

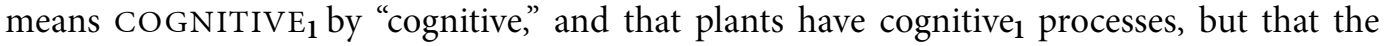
traditional representationalist means COGNITIVE $_{2}$ by "cognitive," and that while human minds have cognitive ${ }_{2}$ processes, plants do not. The project is then to spell out what the difference is between $\operatorname{cognition}_{1}$ and $\operatorname{cognition}_{2}$. It would neatly explain the disagreement of the border wars if this were the case: classical and anti-classical cognitive scientists simply have different concepts invoked by words that are unhappily homophonous. There is, I think, something to this, but it is a mistake to think that mere bank/bank ambiguity is the proper 
diagnosis. If "cognition" is merely ambiguous and refers to distinct and unrelated phenomena, then we would explain the border wars at the cost of undermining cognitive science. Researchers working in different traditions would be investigating distinct kinds of phenomena, despite in many cases using the same experimental paradigms, modeling techniques, and research populations, and despite taking themselves to have disagreements that are not merely verbal. While this embarrassing scenario could conceivably obtain, a methodological commitment to interpretive charity demands we entertain alternative understandings of the practice before we reject it as misguided. And there are less disastrous alternatives in the vicinity: namely, that the scientific concept of cognition exhibits some more complex form of polysemy, so that the various ways that cognitive scientists invoke the word "cognitive" have different standards of application, but are not semantically unrelated.

If philosophers are interested in characterizing the concept of cognition that lives in the practices of contemporary scientists, then the disagreements of the border wars are data in need of accommodation. An ecumenically adequate explication of COGNITION, if it is to be true to these data, must not draw a bright line that legislates which of these items are cognitive and which are not. Rather, it must have an extension that distinguishes which phenomena are clear cases of cognition, which are clearly not cases of cognition, and which are controversial. Such a characterization would require that membership in the extension of COGNITION not be allor-nothing, but a property that can vary somehow without being merely graded in the manner of CLOUDY, or ambiguous in the manner of "bank."

Though the ecumenical approach I advocate here is underexplored with respect to the problem of cognition, there are several "off-the-shelf" models for explications of other concepts that do produce the right sort of graded extensions. For example, several authors have suggested that COGNITION might be fruitfully modeled as a cluster concept (Aizawa 2014, 32; Buckner 2015; Ramsey forthcoming). Prototype or exemplar-based characterizations of concepts (Rosch and Mervis 1975) also provide resources for explaining variations in willingness to ascribe concepts. For example, MAMMAL applies more comfortably to cats and rodents than to whales or monotremes. Likewise, ecumenical adequacy might be achieved by characterizations like Griffiths, Machery and Linquist's (2009) account of the lay concept of INNATENESS in terms of additive conditions, or by accounts like Peter Godfrey-Smith's (2009) of Darwinian populations in terms of continuously varying factors. Other promising models include Daniel Dennett's intentional stance (Dennett 1987) and Stellan Ohlsson's "Darwinian explanatory strategy" (Ohlsson 1993), which provide conceptual explications in terms of explanatory strategies. These accounts produce non-classical extensions, where membership in the extension is indexed to the explanatory goals of an inquirer. John MacFarlane's (2014) assessment-sensitive semantics allow for differential ascriptions of epistemic modal claims and 
evaluative terms like BRAVE and TASTY indexed to "contexts of assessment," so that licit ascriptions of predicates can vary with the evidence or preferences of the ascriber.

So an ecumenical characterization requires a more complex structure than a sectarian characterization that appeals only the devices of necessary or sufficient conditions (or expressions whose extensions are modeled by single classical sets), even if augmented by appeal to vagueness or ambiguity. However, the cost in theoretical and expository complexity could be made up for in other advantages, e.g. by modeling conflicting expert judgments, or making explicit what scientists have learned about cognition, or serving as a tool for explaining cognitive science to non-specialists, or serving as a non-sectarian resource for appeal in related philosophical arguments.

\section{The Benefits of Ecumenical Conceptual Explication}

I argued above that the sectarian explications are poor means for accomplishing the epistemological, public-relations, and metaphilosophical benefits. This was in large part because the sectarian strategy obscures the difference between those claims that cognitive scientists agree on and the claims that remain controversial. An ecumenical explication, by contrast, is adequate only if it represents controversial judgments as controversial. Pursuing ecumenical adequacy requires us to acknowledge, rather than obscure, the limitations of our current knowledge, since explications of the norms for employing COGNITION that incorporate controversial hypotheses can be expected to favor the patterns of judgment exhibited by those who endorse the hypotheses. Despite representing a strong break from existing work on the problem of cognition, the ecumenical strategy does represent a viable approach to the problem.

One might object that an account of cognition that does not settle the open questions of the border wars-at least some of them-is no solution to the problem of cognition at all. ${ }^{9}$ However, the problem of cognition as I described it is anxiety about the lack of any positive characterization of cognition; it is not identical to the open questions of the border wars. The problem of cognition is also motivated by the epistemological, public-relations, and metaphilosophical benefits. An ecumenical explication that to some extent secures these other benefits relieves some of the anxieties associated with the problem of cognition, even if it leaves the disputes of the border wars exactly as they are.

The primary virtue of ecumenical adequacy is that it has the right structure to achieve the epistemological benefit: making explicit what the scientific community has learned about

\footnotetext{
${ }^{9} \mathrm{I}$ am thankful to an anonymous reviewer for putting this objection to me insistently.
} 
cognition since the 1980 os. We do not need a solution to the problem of cognition in order to report various cognitive scientific results, e.g. about the operation of memory mechanisms, or the existence of persistent perceptual illusions, or about what which kinds of algorithms can categorize input, make decisions, or reproduce behavior in humanlike ways. However, without a positive characterization of cognition, it is difficult to understand why researchers use the word "cognition" the way they do, or why many border war disputes-e.g. over plant cognition-are serious scientific disputes rather than merely verbal disputes. Our current border war controversies are motivated by empirical results that erode the contrast between more conservative conceptions of inclusive cognition and anti-classical conceptions of cognition as embodied, embedded, distributed, or realized by plant and microbe processes. In order to make explicit the current state of our knowledge, an explication must reveal what kind of structure the concept COGNITION has such that cognitive scientists can disagree so much about it despite it being so fundamental to their inquiry.

That an ecumenically adequate explication could serve the epistemological function contributes to its potential to serve the public-relations and metaphilosophical functions, since it avoids the pitfalls of a speculative explication by acknowledging the limitations of our current understanding. Nevertheless, just as we can report cognitive scientific results in academic settings without a solution to the problem of cognition, we can communicate them to the public, teach them in the classroom, and exploit them in philosophical argument. However, in public relations and pedagogy these efforts engender more confusion than clarity about the nature of cognition. In classrooms I've visited, students still ask why dreaming and bee dance are of interest to researchers studying something called "cognition." It would be a boon to the public image of cognitive science if there were some compact way of characterizing its object of study, even a fallible and conflicted one, that made sense of the diversity of cognitive scientific perspectives. And though philosophers can make ready use of particular cognitive scientific results, they flounder when trying to talk about cognition or mentality in general. There are competing truisms in the philosophy of mind that "everyone is a functionalist these days" and "nobody believes in functionalism anymore." A positive characterization of cognition that is faithful to our current science would provide a welcome replacement for dogma we've recited insincerely for decades.

None of this is to say that the sectarian strategy should be discarded. The articulation and consideration of speculative hypotheses is a valuable part of theoretical activity, and the sectarian strategy is a more direct means to boundary-policing than the ecumenical strategy. Indeed, the starkest drawback of the ecumenical strategy is that it offers little hope of providing clear answers to the open questions left by the border wars. After all, an ecumenical account is precisely meant not to settle the boundary disputes which were the original theatre of 
deployment for the mark of the cognitive. Whether this is a tolerable drawback depends, of course, on one's goals. If, like most contributors to the current literature on the "mark of the cognitive," boundary-policing is a non-negotiable goal, then ecumenical explication may seem a non-starter. However, an ecumenically adequate explication may be offer indirect promise for boundary-policing. An ecumenical explication aimed at serving the epistemological function should make clear what implicit commitments are shared by cognitive scientists on various sides of the border wars, and which are not. In doing so, an ecumenical explication isolates matters of agreement and disagreement, thus suggesting different terms in which to more fruitfully continue the border wars, while allowing sectarians to see each other as, if not all correct, then disagreeing intelligibly. If through an ecumenical explication of COGNITION we achieve new clarity about the structure of this embattled concept, we may hit upon new ways for philosophers and scientists to settle open questions about the nature and extension of cognition without talking past one another. If so, an ecumenical characterization could be a step along the way to settling the open questions about the border wars. If this possibility were made good then ecumenical explication would be strictly superior to a sectarian explication not only with respect to the epistemological, public relations, and metaphilosophical benefits mentioned; it would also be a less contentious way to promote convergence between rival conceptions of cognition, thus opening new avenues for settling the boundaries of cognition, which is the main concern of the extant contributors to the "mark of the cognitive" literature. However, even if the ecumenical approach were to prove ineffective for policing the boundaries of cognitive science, I contend it would be worth pursuing for its other potential benefits.

\section{Conclusion}

It is a historical accident that the current century's treatment of the problem of cognition has aimed primarily to answer the open questions of the border wars, rather than to serve other functions. The open questions of the border wars motivate further questions about the development of the scientific concept of cognition, about the implicit conceptual knowledge acquired through training in cognitive science, and about the place of minds in the scientific image, as well about other matters that are of broad philosophical interest. The dominant approach to the problem of cognition is one that aims for clarity about the open questions at the expense of these further questions. I have recommended different strategy toward explicating COGNITION in which we aim to make the conceptual change explicit, even at the apparent expense of clear answers to the open questions. Because of the fact of widespread expert disagreement, this ecumenical strategy requires the accommodation of many apparently inconsistent research perspectives by representing controversial elements of the extension of 
COGNITION as controversial. It has been my contention in this paper that an ecumenical explication of the concept of cognition, though unexplored in the contemporary literature, has substantial promise at achieving most of what we would hope for in a solution to the problem of cognition.

Acknowledgments: I am grateful for generous feedback on these ideas from many people, including Joseph McCaffrey, Robert Brandom, Edouard Machery, Mark Sprevak, Zoe Drayson, William Bechtel, three anonymous reviewers, and colleagues at the Society for Philosophy and Psychology, the University of Pittsburgh, the University of Edinburgh, and the University of Glasgow. An earlier version of this paper appears as Chapter 2 of my $\mathrm{PhD}$ dissertation, "Cognition in Practice: Conceptual Development and Disagreement in Cognitive Science" (2016, University of Pittsburgh). I received financial support from University of Pittsburgh Department of Philosophy, the University of Pittsburgh Office of the Provost, and the Wesley C. Salmon Fund.

\section{References}

Adams, F., \& Aizawa, K. (2001). The bounds of cognition. Philosophical Psychology, 14, 43-64. Adams, F., \& Aizawa, K. (2008). The Bounds of Cognition. Malden, MA: Blackwell.

Adams, F., \& Garrison, R. (2013). The mark of the cognitive. Minds \& Machines, 23, 339-352. Aizawa, K. (2014). Extended cognition. In L. A. Shapiro (Ed.), The Routledge Handbook of Embodied Cognition (pp. 31-38). New York: Routledge.

Aizawa, K. (forthcoming). Cognition and behavior. Synthese.

Akagi, M. (2016). Cognition in Practice: Conceptual Development and Disagreement in Cognitive Science (Doctoral dissertation). University of Pittsburgh, Pittsburgh, PA.

Atkinson, R. C., \& Shiffrin, R. M. (1968). Human memory: A proposed system and its control processes. In K. W. Spence, \& J. T. Spence (Eds.), The Psychology of Learning and Motivation: Advances in Research and Theory (Vol. 2, pp. 90-197). New York: Academic Press.

Bacon, F. (1620). Novum Organum. New York: P.F. Collier, 1902.

Block, N. (1980). Troubles with functionalism. In N. Block (Ed.), Readings in Philosophy of Psychology (pp. 171-184). Cambridge, MA: Harvard University Press.

Boorse, C. (1977). Health as a theoretical concept. Philosophy of Science, 44, 542-573.

Bourgine, P., \& Stewart, J. (2004). Autopoiesis and cognition. Artificial Life, 10, 327-345.

Boyd, R. N. (1991). Realism, anti-foundationalism and the enthusiasm for natural kinds. Philosophical Studies, 61, 127-148.

Brooks, R. (1991). Intelligence without representation. Artificial Intelligence, 47, 139-159.

Buckner, C. (2015). A property cluster theory of cognition. Philosophical Psychology, 28, 307-336.

Burgess, A., \& Plunkett, D. (2013a). Conceptual ethics I. Philosophy Compass, 8, 1091-1101.

Burgess, A., \& Plunkett, D. (2013b). Conceptual ethics II. Philosophy Compass, 8, 1102-1110.

Calvo Garzón, F. (2007). The quest for cognition in plant neurobiology. Plant Signaling \& Behavior, 2 , 208-211.

Chalmers, D. J. (2011). A computational foundation for the study of cognition. Journal of Cognitive Science, 12, 323-357.

Chang, H. (2008). Inventing Temperature: Measurement and Scientific Progress. New York: Oxford University Press.

Chemero, A. (2009). Radical Embodied Cognitive Science. Cambridge, MA: MIT Press. 
Chemero, A., \& Silberstein, M. (2008). After the philosophy of mind: replacing scholasticism with science. Journal of Philosophy, 75, 1-27.

Churchland, P. M. (1981). Eliminative materialism and the propositional attitudes. Philosophy of Science, $78,67-90$.

Clark, A. (1997). Being There: Putting Brain, Body and World Together Again. Cambridge, MA: MIT Press.

Clark, A. (2001). Reasons, robots, and the extended mind. Mind and Language, 16, 121-145.

Clark, A. (2008). Supersizing the Mind: Embodiment, Action, and Cognitive Extension. Oxford: Oxford University Press.

Clark, A. (2010). Memento's revenge: the extended mind, extended. In R. Menary (Ed.), The Extended Mind (pp. 43-66). Cambridge, MA: Bradford.

Clark, A., \& Chalmers, D. (1998). The extended mind. Analysis, 58, 7-19.

Cleland, C. E. (2012). Life without definitions. Synthese, 185, 125-144.

Dennett, D. C. (1987). The Intentional Stance. Cambridge, MA: MIT Press.

Eliasmith, C. (2002). The myth of the Turing machine: the failure of functionalism and related theses. Journal of Experimental and Theoretical Artificial Intelligence, 14, 1-8.

Gallagher, S. (2005). How the Body Shapes the Mind. Oxford: Clarendon.

Gettier, E. (1963). Is justified true belief knowledge? Analysis, 23, 121-123.

Gibbs, R. W., Jr. (2005). Embodiment and Cognitive Science. Cambridge: Cambridge University Press.

Godfrey-Smith, P. (2002). Environmental complexity and the evolution of cognition. In R. J. Sternberg, \& J. C. Kaufman (Eds.), The Evolution of Intelligence (pp. 233-249). Mahwah, NJ: Lawrence Erlbaum.

Godfrey-Smith, P. (2009). Darwinian Populations and Natural Selection. Oxford: Oxford University Press.

Greene, J. D., Nystrom, L. E., Engell, A. D., Darley, J. M., \& Cohen, J. D. (2004). The neural bases of cognitive conflict and control in moral judgment. Neuron, 44, 389-400.

Griffiths, P., Machery, E., \& Linquist, S. (2009). The vernacular concept of innateness. Mind and Language, 24, 605-630.

Griffiths, P., \& Stotz, K. (2006). Genes in the postgenomic era. Theoretical Medicine and Bioethics, 27, $499-521$.

Hallin, D. C. (1986). The Uncensored War: The Media and Vietnam. New York: Oxford University Press.

Haslanger, S. (2000). Gender and race: (What) are they? (What) do we want them to be? Noûs, 34, $31-55$.

Hurley, S. L. (1998). Consciousness in Action. Cambridge, MA: Harvard University Press.

Hutchins, E. (1995). Cognition in the Wild. Cambridge, MA: MIT Press.

Lewis, D. K. (1973). Counterfactuals. Cambridge, MA: Harvard University Press.

Lilienfeld, S. O., \& Marino, L. (1995). Mental disorder as a Roschian concept: A critique of Wakefield's 'harmful dysfunction' analysis. Journal of Abnormal Psychology, 104, 411-420.

Lyon, P. (2006). The biogenic approach to cognition. Cognitive Processing, 7, 11-29.

MacFarlane, J. (2014). Assessment Sensitivity: Relative Truth and Its Applications. Oxford: Clarendon. Machery, E. (2009). Doing without Concepts. Oxford: Oxford University Press.

Machery, E. (2012). Why I stopped worrying about the definition of life... and why you should as well. Synthese, 185, 145-164.

Maturana, H. R., \& Varela, F. (1980). Autopoiesis and Cognition: the Realization of the Living. Boston: D. Reidel.

Noë, A. (2006). Action in Perception. Cambridge, MA: MIT Press.

Ohlsson, S. (1993). Abstract schemas. Educational Psychologist, 28, 51-66.

Orlandi, N. (2014). The Innocent Eye: Why Vision Is Not a Cognitive Process. New York: Oxford University Press.

Prinz, J. (2004). Gut Reactions: A Perceptual Theory of Emotions. Oxford: Oxford University Press.

Putnam, H. (1967). The mental life of some machines. In H.-N. Castañeda (Ed.), Intentionality, Minds, and Perception. Detroit: Wayne State University Press.

Quine, W. V. O. (1960). Word and Object. Cambridge, MA: MIT Press. 
Ramsey, W. M. (1992). Prototypes and conceptual analysis. Topoi, 11, 59-70.

Ramsey, W. M. (2007). Representation Reconsidered. Cambridge: Cambridge University Press.

Ramsey, W. M. (forthcoming). Must cognition be representational? Synthese.

Robbins, P., \& Aydede, M. (Eds.). (2008). The Cambridge Handbook of Situated Cognition. Cambridge: Cambridge University Press.

Rosch, E., \& Mervis, C. B. (1975). Family resemblance: Studies in the internal structure of categories. Cognitive Psychology, 7, 573-605.

Rowlands, M. (2009). Extended cognition and the mark of the cognitive. Philosophical Psychology, 22, 1-19.

Rowlands, M. (2010). The New Science of the Mind: From Extended Mind to Embodied Phenomenology. Cambridge, MA: MIT Press.

Rumelhart, D. E. (1989). The architecture of mind: a connectionist approach. In M. I. Posner (Ed.), Foundations of Cognitive Science (pp. 133-159). Cambridge, MA: MIT Press.

Rupert, R. (2004). Challenges to the hypothesis of extended cognition. Journal of Philosophy, 51, $389-428$.

Rupert, R. (2009). Cognitive Systems and the Extended Mind. Oxford: Oxford University Press.

Rupert, R. (2013). Memory, natural kinds, and cognitive extension; or, Martians don't remember, and cognitive science is not about cognition. Review of Philosophy and Psychology, 4, 25-47.

Shapiro, L. A. (2013). Dynamics and cognition. Minds \& Machines, 23, 353-375.

Smart, J. J. C. (1959). Sensations and brain processes. Philosophical Review, 68, 141-156.

Sprevak, M. (2009). Extended cognition and functionalism. The Journal of Philosophy, 106, 503-527.

Stewart, J. (1996). Cognition = life: implications for higher-level cognition. Behavioural Processes, 35, $311-326$.

Stich, S. (1983). From Folk Psychology to Cognitive Science: The Case against Belief. Cambridge, MA: Bradford.

Thelen, E., \& Smith, L. B. (1994). A Dynamic Systems Approach to the Development of Cognition and Action. Cambridge, MA: MIT Press.

Thompson, E. (2010). Mind in Life: Biology, Phenomenology, and the Sciences of the Mind. Cambridge, MA: Harvard University Press.

Trewavas, A. (2003). Aspects of plant intelligence. Annals of Botany, 92(1-20).

Tulving, E. (1972). Episodic and semantic memory. In E. Tulving, \& W. Donaldson (Eds.), Organization of Memory (pp. 381-403). New York: Academic Press.

Turing, A. M. (1950). Computing machinery and intelligence. Mind, 59, 433-460.

Tversky, A., \& Kahneman, D. (1974). Judgment under uncertainty: Heuristics and biases. Science, 185, 1124-1131.

van Duijn, M., Keijzer, F., \& Franken, D. (2006). Principles of minimal cognition: casting cognition as sensorimotor coordination. Adaptive Behavior, 14, 157-170.

van Gelder, T. (1998). The dynamical hypothesis in cognitive science. Behavioral and Brain Sciences, 21, 615-665.

Varela, F., Thompson, E., \& Rosch, E. (1991). The Embodied Mind: Cognitive Science and Human Experience. Cambridge, MA: MIT Press.

von Helmholtz, H. (1867). Handbuch der physiologischen Optik. Leipzig: Voss.

Wakefield, J. C. (1992). The concept of mental disorder: On the boundary between biological facts and social values. American Psychologist, 47, 373-388.

Walter, S. (2010). Cognitive extension: the parity argument, functionalism, and the mark of the cognitive. Synthese, 177, 285-300.

Webb, B. (1994). Robotic experiments in cricket phonotaxis. In D. Cliff, P. Husbands, J.-A. Meyer, \& S. W. Wilson (Eds.), From Animals to Animats 3: Proceedings of the Third International Conference on Simulation of Adaptive Behavior (pp. 45-54). Cambridge, MA: MIT Press.

Wilson, M. (2006). Wandering Significance: An Essay on Conceptual Behavior. Oxford: Clarendon.

Wilson, R. A. (2010). Review of Robert D. Rupert's Cognitive systems and the extended mind. Notre Dame Philosophical Reviews, March 7, 2010, https://ndpr.nd.edu/news/24309-cognitivesystems-and-the-extended-mind/. 